\title{
A etnomatemática da roladeira mossoroense
}

Francisca Vandilma Costa

John A. Fossa

\begin{abstract}
Resumo
O presente artigo investiga um instrumento popular mossoroense, a roladeira, para o transporte d'água. Descreve algumas das suas características fenomenológicas e matemáticas e ainda ilustre como poderá ser usado na Educação Matemática, promovendo um "dialogo" entre a matemática acadêmica e a etnomatemática.
\end{abstract}

Palavras-chave: educação matemática; etnomatemática; roladeira.

\section{Abstract}

The present work investigates a popular instrument, used in Mossoró - RN for transporting water. It describes some of this instrument's phenomenological and mathematical characteristics and illustrates how it can be used in Mathematics Education, promoting a "dialogue" between academic mathematics and ethnomathematics.

Keywords: mathematics education; ethnomathematics; roladeira.

\section{Introdução}

Uma das tendências atuais mais importantes da Educação Matemática é a Etnomatemática. O ponto de partida básico dessa tendência é a suposição de que vários grupos culturalmente identificáveis têm desenvolvido conceitos e procedimentos matemáticos que, embora sejam diferentes dos da matemática acadêmica, suprem as suas necessidades. Do ponto de vista pedagógico, o conhecimento etnomatemático poderá ser utilizado de várias maneiras para propiciar ao aluno uma experiência educacional mais rica. Mencionamos apenas alguns exemplos. 
Em primeiro lugar, a etnomatemática poderá motivar o aluno a se interessar pela disciplina e superar o tão comum "pavor da matemática". Isto se dá quando o aluno percebe que membros do seu próprio grupo fazem a matemática e que, portanto, essa ciência não é restrita a um pequeno número de superdotados. Ainda mais importante, porém, podemos conceber o conhecimento etnomatemático como parte da base cognitiva que o aluno traz consigo para a sala de aula. Desta forma, o conhecimento prévio do aluno se torna não somente um ponto de partida para novas aprendizagens, mas também um interlocutor num verdadeiro diálogo com a matemática acadêmica. Observamos também que a etnomatemática aborda problemas práticos e tem uma forte tendência a ser holística. Esses característicos podem proporcionar, ao aluno, contextos que dão significado às abstrações da matemática acadêmica e, ao professor, meios para trabalhar inter- e/ou transdisciplinarmente.

A aplicação pedagógica da etnomatemática, então, envolve dois momentos distintos, a saber, a investigação etnográfica das práticas matemáticas de um determinado grupo e a inserção das referidas práticas na sala de aula. No que segue, faremos uma pequena apresentação de uma prática relacionada com a etomatemática do Estado do Rio Grande do Norte - a roladeira mossoroense -, seguida por algumas reflexões sobre possíveis aplicações da mesma no ensino da matemática.

\section{A Roladeira}

Caracterizada por baixos níveis de chuva e altas temperaturas, devido à sua localização numa região norteriograndense semi-árida, a cidade de Mossoró tem de enfrentar o grande problema do suprimento d'água para as necessidades quotidianas. Claramente, o referido problema pode ser analisado em várias subpartes, como o armazenagem d'água, a sua purificação, a sua conservação e assim por diante. A subparte que será do nosso interesse, no entanto, é a do transporte d'água dos rios, poços, chafarizes públicos ou outros lugares de origem para os lugares de uso, principalmente as residências que não têm água encanada. Para tanto, o uso de certos meios, como o galão ${ }^{1}$, a ancoreta ${ }^{2}$ e a pipa ${ }^{1}$, são bem conhecidos. Há também outro

\footnotetext{
${ }^{1}$ Duas latas que podem ser carregadas no ombro de um homem por meio de um pau roliço em que
} são amarradas duas cordas nas suas pontas.

${ }^{2}$ Barril pequeno que serve para transporte d'água ou outros líquidos no dorso de jumentos (LAROUSE, 1982). 
expediente simples, embora menos conhecido fora da cidade de Mossoró, a roladeira. Usada desde o indício do século XIX, a roladeira é um barril artesanal feito de madeira, atravessado por rodas e aros de aço, que pode ser puxado por uma pessoa por meio de uma corda ou um aro de ferro (ver Foto 1).

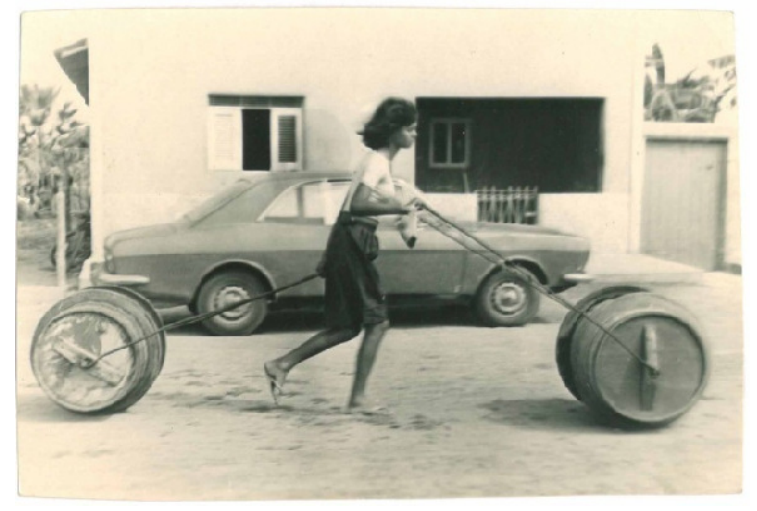

Foto 1. A Roladeira Mossoroense.

Fonte: Museu Municipal de Mossoró-RN, 2004.

Conforme os arquivos do historiador local Sr. Raimundo Brito $^{2}$, as primeiras roladeiras consistiam apenas em um barril atravessado por um pau roliço que podia ser arrastado por meio de uma corda de quatro braças com laços nas pontas. Isto fica claro no depoimento dado ao referido pesquisador, pois o informante disse que

... quando cheguei, com 11 anos de idade, para estudar no Colégio Santa Luzia, em 1912, as roladeiras já eram muito usadas no transporte d'água. Elas constavam de um simples barril atravessado no sentido longitudinal por um pau roliço sobrando em cada texto uma ponta de uns 20

\footnotetext{
${ }^{1}$ Barril grande que serve para transportar água em carroças que são puxadas por jumentos.

${ }^{2}$ Raimundo Soares de Brito nasceu em Caraúbas (1920) e é amante de história, tendo dedicado
} grande parte de sua vida ao garimpo de informações sobre Mossoró e o Rio Grande do Norte. Detém um dos maiores acervos sobre a cidade de Mossoró. Ver Cidadania (2002). Agradecemos ao Sr. Brito o acesso aos referidos arquivos. Observamos que ele e os outros que deram depoimentos para nós consentiram a ser citados nominalmente no presente artigo. 
centímetros. Eram arrastados por meio de uma corda de quatro braças de comprimento cujas pontas terminavam em laços. (R.B., 2004)

O próprio pesquisador relata que “Eu, quando menino em 1926/1927, já via meu pai colocar água para gasto com roladeira na minha casa". O arquivo de Raimundo Brito contém, no entanto, depoimentos sobre o uso da roladeira que remonta a períodos ainda mais afastados do presente. É o caso da afirmação do cidadão João Felipe de Oliveira que assevera que, em 1905, era criança, mas já ajudava o seu tio, Josino Joaquim de Oliveira, a arrastar roladeiras pelos caminhos do bairro onde morava. O mesmo depoimento esclarece que "as roladeiras eram feitas de quintos de vinho português que custavam, quando vazios, 2.500 réis".

Há especulação que a roladeira seja de origem cearense, mais precisamente das cidades de Crato e Juazeiro do Norte. Nossas investigações, porém, não forneceram evidência alguma que apoiasse essa hipótese. Seja isto como for, parece certo que o instrumento já foi bem conhecido em Mossoró no final do século XIX e início do século XX e, uma vez estabelecido nessa cidade, irradiou-se para toda a zona oeste do estado e cidades vizinhas do Estado do Ceará. Atualmente, a roladeira ainda é usada, especialmente nas áreas mais rurais da região. Tivemos, por exemplo, oportunidade de indagar vários moradores do Riacho Grande, uma localidade da zona rural de Mossoró, sobre a existência da roladeira na sua comunidade e constatamos que ela é um artifício constantemente presente entre eles. Também obtemos dos referidos moradores vários depoimentos sobre a importância desse instrumento; foi até um fator econômico importante em certa época passada, pois houve quem se sustentava fazendo transporte d'água para as residências de Mossoró arrastando roladeiras pelas ruas da cidade.

Devido à sua fragilidade, as primeiras roladeiras, no entanto, eram arrebentadas com muita freqüência. Com a abertura da oficina de tanoaria (ver Foto 2), em 1942, de Antônio Pereira Pinto, um imigrante que havia chegado ao Mossoró de Portugal em 1936 e que era conhecido na cidade pelo apelido "Antônio Português", a roladeira começou a ser aperfeiçoada. Nas palavras de Deífilo Gurgel (1999, p. 38), "os costumes e os usos do povo sofrem constantemente, o impacto das descobertas científicas e técnicas das classes mais favorecidas da sociedade e, quando não desaparecem de vez, disfarça-se em novas expressões, para poder sobreviver". Foi isto que aconteceu com a roladeira, que sofreu vários melhoramentos na oficina de "Antônio Português", incluindo a fabricação de barris mais resistentes e o uso de aros de aço, em vez de cordas, para puxar o instrumento. 


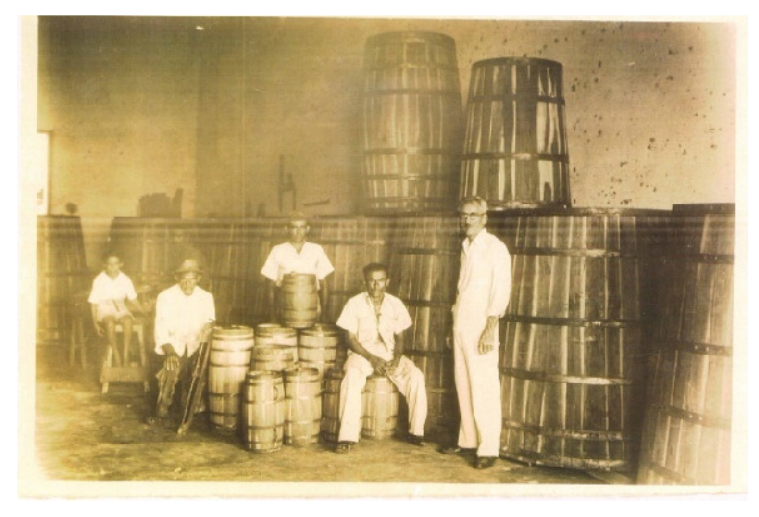

Foto 2. Antônio Português e sua Oficina de Tanoaria.

Fonte: Arquivo Museu Municipal de Mossoró, 2004.

As palavras de Deífilo Gurgel, citadas acima, poderão nos levar a concluir que, com o advento de água encanada, o uso da roladeira não sobreviveria em Mossoró. No entanto, já vimos que isto não aconteceu, pois esse instrumento é ainda usado nesse local, embora seja mais comum nas zonas rurais onde a água encanada ainda não tem chegado. De fato, ainda existe fazedores de roladeira na região, como é o caso do Sr. Raimundo Ferreira Lima, conhecido popularmente por Raimundo Vitor, da Serra Mossoró. Atualmente com 76 anos de idade, vem construindo roladeiras, por encomenda, desde os meados da década de 40 no valor hoje de 70 a 120 reais. Raimundo Vitor, apesar do fato de que tem apenas pouca escolaridade, demonstra o conhecimento da matemática e vê a presença clara dessa ciência nas suas medidas lineares e de capacidade. Faz roladeiras de 5 a 8 latas, feitas com madeira da região, como pau branco, cumaru e angico. O não uso do sistema métrico oficial mostra, como aponta Ubiratan D'Ambrosio (1998), que a prática da etnomatemática faz referência a linguagens específicas, códigos de comportamentos, simbologias, práticas sociais e sensibilidades próprios aos contextos culturais específicos em que estão inseridas e que esses podem diferir dos contextos sociais maiores de que são uma parte. 
É importante observar que a etnomatemática geralmente tem finalidades distintas das da matemática acadêmica e, portanto, poderá ser enganador julgar práticas etnomatemáticas pelos padrões da matemática acadêmica. Como Teresa Vergani (2000, p. 33) afirma,

O conhecimento matemático adquire validade na medida em que se integra, localmente, num grupo humano. A "universalidade" é relativisada pelo crédito - pragmático e científico - que a comunidade lhe atribui. A matemática, modelizando situações ou estruturando problemas, faz parte do diálogo vital que o homem teve com o meio. A educação etnomatemática é um processo antropológico que veicula todas as componentes do nosso conceito de cultura:

- $\quad$ aspectos semióticos, simbólicos e comunicacionais

- $\quad$ aspectos sócio-políticos, de organização do trabalho, de relações com o poder

- $\quad$ aspectos cognitivos, modos de saber

- $\quad$ aspectos tecnológicos (desde o domínio das condições naturais à criação de espaços de lazer).

Desta forma, a etnomatemática geralmente preocupa-se com problemas práticos específicos e não tenta articular, como a matemática acadêmica, sistemas gerais. Mesmo assim, por debruçar-se sobre problemas práticos, a etnomatemática está atenta a uma grande variedade de relações entre a matemática e outras áreas de saber. Assim, a roladeira é relacionada não somente a conceitos matemático e físicos, mas também, por exemplo, a problemas de escassez de água, a falta de uma política hídrica adequada para o pequeno agricultor nordestino. A educação etnomatemática, em conseqüência, tem uma visão holística e facilita tais abordagens pedagógicas como a interdisciplinaridade, a transdisciplinaridade e a pedagogia dos projetos ${ }^{1}$.

A educação etnomatemática poderá ainda servir outras funções além das citadas no início no presente artigo, pois poderá ser o ponto de partida para uma análise crítica que traria à tona as conseqüências nocivas de certos costumes praticados pelos membros de uma comunidade. No caso da roladeira, por exemplo, o valor desse instrumento poderá ser

\footnotetext{
${ }^{1}$ Para uma discussão mais detalhada sobre a etnomatemática e a pedagogia dos projetos, ver
} Costa (2005). 
contrastado com o do uso, para o transporte e o armazenagem d'água, de tambores plásticos, originalmente contendo produtos agrotóxicos. Os referidos tambores, denominados "bombonas" em Mossoró, são reaproveitáveis e, em certos respeitos, bastante convenientes; no entanto, seu reaproveitamento pode causar sérios danos à saúde.

Finalmente, observamos mais um aspecto do uso da roladeira que ajuda a explicar porque essa prática não foi completamente abandonada, mesmo com a chegada de água encanada. A característica a qual aludimos é o fato de que tornou-se parte do folclore e, portanto, da tradição cultural, da região. Nas palavras de Nilza Megale (1999, p. 17),

O fato folclórico, como expressão da vida peculiar de uma coletividade, não acompanha a moda, mas muitas vezes se contrapõe a ela, assim como as artes e técnicas eruditas modernas, ainda que essas possam lhe dar origem. (exemplo: cerâmicas, bordados, etc.). Apesar de tradicional, ele pode ser originário de uma forma erudita de cultura, que se despersonalizou e foi aceita coletivamente.

O anonimato com referência aos origens, sua aceitação coletiva, transmissão oral e funcionalidade são vários dos aspectos da roladeira que ajudam a garantir um lugar para esse instrumento na folclore mossoroense. Desta forma, uma investigação etnomatemática da roladeira ajudará o aluno a resgatar conhecimentos tradicionais da sua própria terra, proporcionando a ele valores positivas sobre esses conhecimentos e sobre seu lugar como uma parte deles.

\section{Aspectos da Matemática Presentes na Roladeira}

Já mencionamos acima que uma investigação etnomatemática da roladeira naturalmente nos levaria a uma discussão de sistemas de pesos e medidas. A discussão poderia englobar tanto o sistema métrico oficial, quanto o sistema etnomatemático usado pelos fazedores de roladeiras e outros sistemas. O problema da conversão entre sistemas poderia ser investigado empiricamente e matematicamente, proporcionando ao aluno uma compreensão maior das diferenças entre a metodologia das ciências naturais e a da matemática. A referida investigação também favoreceria o desenvolvimento de uma compreensão intuitiva de tais importantes conceitos matemáticos como o M.D.C., o M.M.C. e o algoritmo da divisão, entre outros.

Voltaremos agora a nossa atenção para as partes e a construção da roladeira, com o intuito de ilustrar alguns dos outros aspectos matemáticos nela presentes. Para tanto faremos referência à Figura 1, um desenho do referido instrumento e suas partes de dois pontos de vista. 


\section{1}

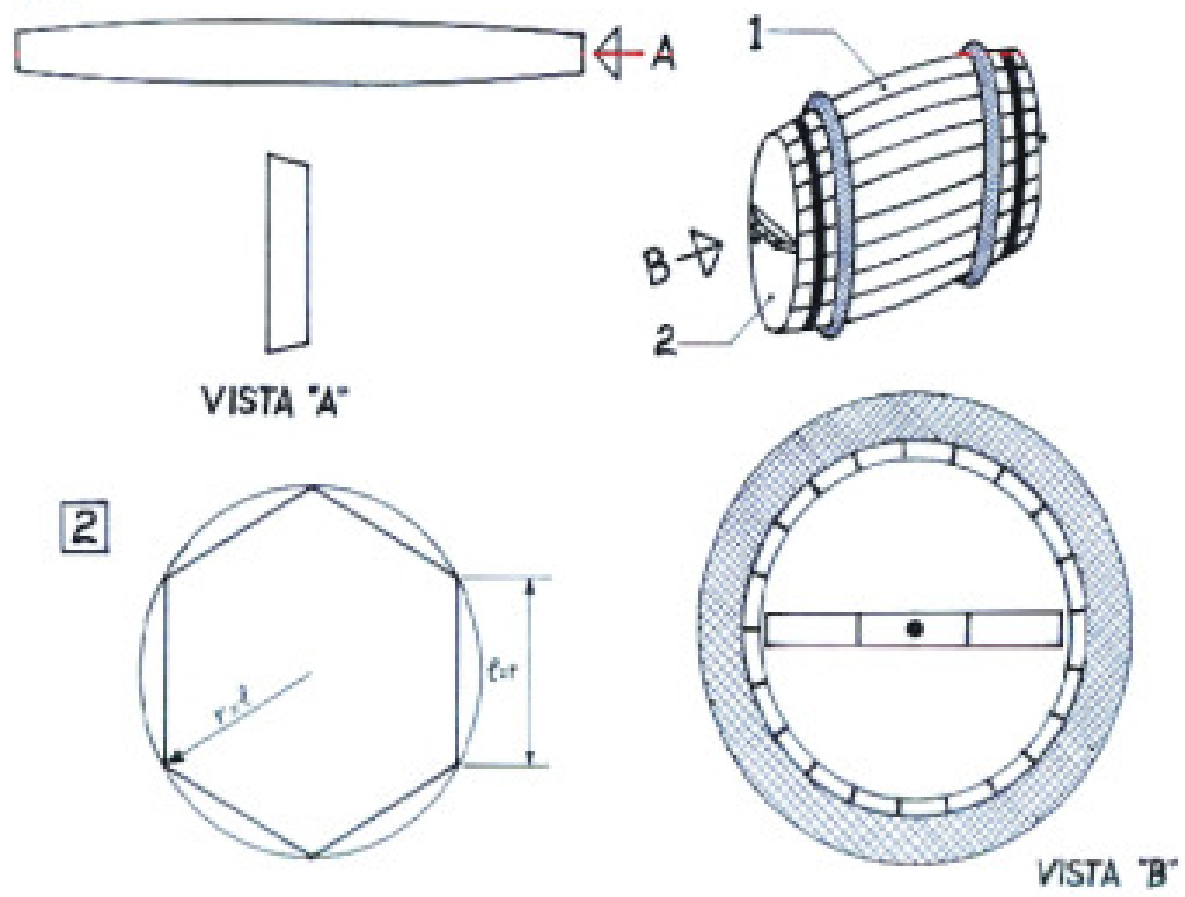

Figura 1. Vistas da Roladeira.

Fonte: Sousa $(2004)^{1}$.

Na primeira parte da Figura 1, "Vista A", uma das partes da roladeira, chamada duela, ou popularmente costela, é destacada. Consiste em uma tira de madeira de formato arqueado cujas extremidades laterais possuem ligeiros ajustes oblíquos, os quais são feitos por uma suta e uma plaina. Tal forma objetiva facilitar o encaixe perfeito junto as demais costelas e dessa maneira dá o formato circular final da roladeira. Isso se consegue devido a ponta de cada costela ter uma redução a ângulos menores de $90^{\circ}$. É interessante observar que estas costelas são agrupadas uma a uma e amarradas por meio de um arco circular de metal de ferro. Todos esses aspectos da construção da roladeira podem proporcionar ocasião de vários assuntos matemáticos; é também interessante, entretanto, mostrar as detalhes da construção com o intuito de ver como um

1 SOUSA, Francisco de Assis de. Desenhista e professor que contribuiu para essa pesquisa investigativa em 2004. 
instrumento como esse - um barril feito de madeira que não vaza água - pode ser construído artesanalmente. Isto é importante, especialmente na nossa sociedade contemporânea em que quase tudo parece ser industrializado, para resgatar o valor positivo dos conhecimentos não acadêmicos e das habilidades do artesão que freqüentemente tem pouca ou nenhuma escolaridade. ${ }^{1}$

A segunda parte da Figura 1, "Vista B", mostra a tampa da roladeira, chamada texto na comunidade mossoroense. A tampa tem o formato de um círculo, o que obviamente favorece uma discussão intuitiva dessa figura geométrica e as suas propriedades. Seria especialmente importante obter uma apreciação intuitiva da propriedade constitutiva da circunferência, que é o lugar planar dos pontos eqüidistantes do centro do círculo.

As estratégias pedagógicas mencionadas no parágrafo anterior são interessantes e têm uma forte tendência de motivar o aluno e proporcionar a ele compreensão intuitiva das abstrações matemáticas e as suas aplicações. A parte primorosa da educação etnomatemática, no entanto, é somente alcançada com uma investigação mais detalhada da própria prática do artesão. No caso da tampa da roladeira precisamos indagar como, de modo artesanal, se faz tampas tão redondos e que ajustam ao barril de forma a não ter vazamentos! Quando pusemos essa questão ao Sr. Raimundo Vitor, fazedor de roladeiras mencionado acima, ele respondeu que essa é a "melhor pergunta". Em seguida, foi buscar um compasso feito por ele próprio com dois pedaços de ferro e explicou: "Eu monto a roladeira juntando as costelas uma a uma dentro do arco e então prontas, venho com o compasso e divido em seis medidas iguais à circunferência. Isto porque só dar certo se for seis, para ficar ajustado o texto e não vazar a água, agora não sei porque isso, não." A razão que dá certo dividir em seis partes iguais é que o hexágono regular é composto de seis triângulos eqüiláteros e, em conseqüência. quando essa figura está inscrita numa circunferência o raio da mesma é igual ao lado do hexágono (ver Figura 2).

\footnotetext{
${ }^{1}$ Para uma discussão de uma problemática semelhante, envolvendo a construção artesanal de
} barcos no Estado de Pará, ver Lucena (2005). Nessa obra consta também a construção artesanal de um compasso, como será atestada, mais adiante no presente texto, também no caso da roladeira. 


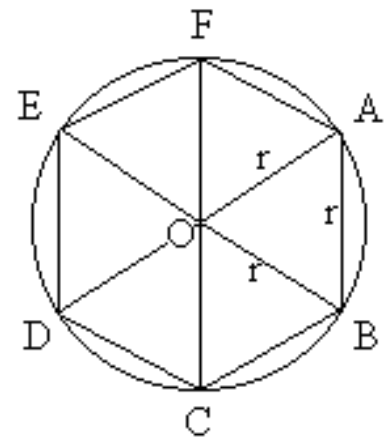

Figura 2. O Hexágono Inscrito na Circunferência.

Esse tipo de investigação leva o aluno não somente a um maior entendimento da atividade prática de fazer roladeiras, mas também a uma maior compreensão de conceitos matemáticos e de importantes relações entre esses conceitos. Desta forma, o diálogo entre a etnomatemática e a matemática promove o que Richard Skemp (1989) chama compreensão relacional da matemática e seus vários papéis culturais. Isto é, promove a construção de redes conceituais amplas, as quais constituem, segundo a teoria construtivista, a base do conhecimento profundo de qualquer assunto, e coaduna com a natureza holística da etnomatemática.

\section{Conclusão}

Há ainda outros aspectos da roladeira que poderíamos assinalar como sendo úteis no ensino da matemática. O nosso propósito, porém, não é fazer uma catalogação exaustiva de todas as maneiras em que o referido aparelho poderia ser usada na sala de aula. Queríamos apenas ilustrar como a educação etnomatemática, consistindo em uma investigação antropológica de práticas sociais e um diálogo dessas práticas com a matemática acadêmica, poderá ser um poderoso instrumento para o ensino da matemática. Ao mesmo tempo, queríamos resgatar um pouco do conhecimento tradicional de uma parte do nosso Estado, tornando-o mais conhecido entre os educadores brasileiros. 


\section{Referências}

CIDADANIA. Secretaria de Cidadania da Prefeitura Municipal de Mossoró. Ano 2- no 6. mar. 2002. COSTA, Francisca Vandilma. Pedagogia de Projetos e Etnomatemática: Caminhos e Diálogos na Zona Rural de Mossorá/RN. Dissertação de Mestrado. Programa de Pós-Graduação em Educação. Natal: UFRN, 2005.

D'AMBROSIO, Ubiratan. Etnomatemática: elo entre as tradições e a modernidade. 2.ed. Belo Horizonte: Autêntica, 2002. (Coleção Tendências em Educação Matemática).

GURGEL, Deífilo. Espaço e tempo do folclore potiguar: folclore geral: folclore brasileiro. Natal-Rn, Prefeitura do Natal. FUNCART: Secretaria do $4^{\circ}$ centenário, 1999.

LAROUSE. Novíssima enciclopédia. Delta S.A. Rio de Janeiro, 1982.

LUCENA, Isabel Cristina Rodrigues de. Educação Matemática, Ciência e Tradição: Tudo no Mesmo Barco. Tese de Doutorado. Programa de Pós-Graduação em Educação. Natal: UFRN, 2005.

MEGALE, Nilza B. Folclore brasileiro. ed. Vozes: Petropóles, 1999.

NONATO, Raimundo, Calepino potiguar. Coleção mossoroense. Série "C", vol. CXIX, 1980.

SKEMP, Richard. Mathematics in the Primary School. Routledge: London, 1989.

VERGANI, Teresa. Educação etnomatemática: o que é?. Lisboa: Pandora, 2000.

John A. Fossa - professor da Universidade Federal do Rio Grande do Norte. jfossa@oi.com.br

Francisca Vandilma Costa - professora do Instituto de Formação Superior Presidente Kennedy. franvand@bol.com.br 